\title{
Polyoxometalate/laccase-mediated oxidative polymerization of catechol for textile dyeing
}

\author{
Suyeon Kim • Carla Silva • Dmitry V. Evtuguin • \\ José A. F. Gamelas • Artur Cavaco-Paulo
}

Received: 13 July 2010 /Revised: 11 August 2010/Accepted: 1 October 2010 /Published online: 16 October 2010

(C) Springer-Verlag 2010

\begin{abstract}
The synergistic effect between polyoxometalates (POMs), namely $\mathrm{K}_{5}\left[\mathrm{SiW}_{11} \mathrm{~V}^{\mathrm{V}} \mathrm{O}_{40}\right] \cdot 11 \mathrm{H}_{2} \mathrm{O}$ and $\mathrm{H}_{5}\left[\mathrm{PMo}_{10}\right.$ $\left.\mathrm{V}_{2}{ }_{2} \mathrm{O}_{40}\right] \cdot 13 \mathrm{H}_{2} \mathrm{O}$ and laccase from ascomycete Myceliophthora thermophila has been employed for the first time in oxidative polymerization of catechol. Such a laccase-mediator system allowed the formation of a relatively high molecular weight polycatechol as confirmed by size exclusion chromatography and electrospray ionization mass spectrometry (ESI-MS) (3990 Da when using $\mathrm{K}_{5}\left[\mathrm{SiW}_{11} \mathrm{~V}^{\mathrm{V}} \mathrm{O}_{40}\right] \cdot 11 \mathrm{H}_{2} \mathrm{O}$ and $3600 \mathrm{Da}$ with $\mathrm{H}_{5}\left[\mathrm{PMo}_{10} \mathrm{~V}_{2} \mathrm{O}_{40}\right] \cdot 13 \mathrm{H}_{2} \mathrm{O}$ ). The synthesized polymers were applied as dyes for the dyeing of flax fabrics. The color intensity of flax fabrics colored with polymer solutions was evaluated by diffuse reflectance spectrophotometry via $k / s$ measurements $(+10 \%$ of fixation ratio). A new synthetic process allowed a dyeing polymer, provided upon flax coloration, better color fixation and color resistance when compared to that obtained by conventional synthesis with laccase solely or with addition of organic mediator (1-hydroxybenzotriazole).
\end{abstract}

Keywords Polyoxometalate $\cdot$ Laccase $\cdot$ Catechol . Mediator $\cdot$ Polymerization

Suyeon Kim and Carla Silva equally contributed to this work.

S. Kim · C. Silva · A. Cavaco-Paulo $(\triangle)$

Textile Engineering Department, University of Minho, 4800-058 Guimarães, Portugal

e-mail: artur@det.uminho.pt

D. V. Evtuguin

CICECO/Department of Chemistry, University of Aveiro,

3810-193 Aveiro, Portugal

J. A. F. Gamelas

Department of Chemical Engineering, University of Coimbra,

Pólo II-R. Sílvio Lima,

3030-790 Coimbra, Portugal

\section{Introduction}

Polyoxometalates (POMs) are early transition metal oxygenanion clusters with relevant structural and electronic properties, widely studied as oxidation catalysts for homogeneous and heterogeneous organic synthesis (Kozhevnikov 1998; Long et al. 2007; Neumann 1998). Generally, the approaches used to produce POM-based clusters are extremely simple, consisting of acidifying of an aqueous solution containing the relevant pre-hydrolyzed metal oxide anions (molybdate, tungstate, vanadate) (Long et al. 2007). POMs were proposed as highly selective renewable agents or catalysts for kraft pulp delignification and claimed as suitable alternative to chlorine-based ecologically hazardous bleaching reagents and to the conventional oxygen alkaline bleaching (Gaspar et al. 2007). Applied as catalysts under aerobic conditions, POMs oxidize the residual lignin in kraft pulp, and the reduced form of POMs is re-oxidized by molecular oxygen at the same process stage (Gaspar et al. 2004, 2007). Laccases (EC 1.10.3.2), are multicopper polyphenol oxidases capable of oxidizing phenols by hydrogen atom abstraction resulting in the formation of the corresponding phenoxyl radicals, used with or without the mediators (Riva 2006; Morozova et al. 2007). In a series of previous studies, POMs were applied as inorganic redox mediators in the laccase-mediator system (LMS) for pulp delignification. In the catalytic cycle, POMs oxidize the residual lignin, and the reduced POMs are re-oxidized by laccase at the same process step (Balakshin et al. 2001; Gamelas et al. 2005; Tavares et al. 2004). The LMS applied for delignification in the bleaching process requires fewer chemicals and presents moderate oxidative damage of pulp polysaccharides as was proved by evaluation of pulp intrinsic viscosity (Tavares et al. 2004; Gamelas et al. 2005). Recently, an improved LMS have 
been proposed where the continuous oxidation of residual lignin in pulp and the re-oxidation of POM with laccase are performed simultaneously in separate reactors thus avoiding a pulp contact of pulp with laccase and improving the selectivity of the delignification (Gamelas et al. 2007). The potential of laccase for polymerization, crosslinking, and functionalization of various phenolic compounds and lignin has been widely studied (Gronqvist et al. 2003; Mattinen et al. 2008). The enzymatic oxidation of catechol, a known laccase substrate, typically involves the formation of a free cation radical. Further nonenzymatic reactions may take place resulting in colored dimeric, oligomeric, and polymeric molecules (Mattinen et al. 2008; Aktas and Tanyolac 2003; Pilz et al. 2003).

In the present work, the effects of inorganic mediators, such as the vanadium-substituted polyoxometalates, $\mathrm{K}_{5}\left[\mathrm{SiW}_{11} \mathrm{~V}^{\mathrm{V}} \mathrm{O}_{40}\right] \cdot 11 \mathrm{H}_{2} \mathrm{O}$ and $\mathrm{H}_{5}\left[\mathrm{PMo}_{10} \mathrm{~V}_{2} \mathrm{~V}^{\mathrm{V}} \mathrm{O}_{40}\right] \cdot 13 \mathrm{H}_{2} \mathrm{O}$, on the laccase catalyzed oxidative polymerization of catechol have been studied. Furthermore, the produced polycatechols employing LMS were evaluated as colorants for the flax fabrics. The color intensity after fabrics coloration with polymer solutions was evaluated by diffuse reflectance spectroscopy via $k / s$ measurement.

\section{Materials and methods}

Enzyme, reagents, and fabrics

The polyoxometalates (mediators) $\mathrm{K}_{5}\left[\mathrm{SiW}_{11} \mathrm{~V}^{\mathrm{V}} \mathrm{O}_{40}\right] \cdot 11 \mathrm{H}_{2} \mathrm{O}$ and $\mathrm{H}_{5}\left[\mathrm{PMo}_{10} \mathrm{~V}_{2} \mathrm{~V}_{40}\right] \cdot 13 \mathrm{H}_{2} \mathrm{O}$ were synthesized using methods described in literature (Domaille 1984; Tsigdinos and Hallada 1968). Laccase $\left(306 \mathrm{U} / \mathrm{mL}, 20{ }^{\circ} \mathrm{C}\right)$ from the ascomycete $M$. thermophila (Novozym ${ }^{\circledR} 51,003$ ) was supplied by Novozymes Bagsvaerd, Denmark. One hundred percent raw woven flax fabric having 14/14 yarns (warp/weft) per centimeter was used for coloration after alkaline scouring. All chemicals used, including 1-hydroxybenzotriazole (HBT), were commercially available analytical grade products purchased from Sigma-Aldrich Chemical Co. and used without further purification. The anionic surfactant, Lutensol AT25, was kindly supplied by BASF (Ludwigshafen, Germany).

\section{Oxidative polymerization of catechol and flax coloration}

A $10 \mathrm{mM}$ catechol solution was prepared in $0.1 \mathrm{M} \mathrm{Na}-$ acetate buffer at $\mathrm{pH} 5$. For the oxidation of catechol, the reaction mixtures contained laccase, alone or together with polyoxometalates as mediators. HBT, most frequently used as a laccase mediator, was also applied in the LMS solution to compare the mediation effect with those of polyoxometalates. A control experiment with POM without laccase was also performed to confirm enzyme catalysis. In each pot, $2 \mathrm{U} \mathrm{mL}^{-1}$ of laccase and $2 \mathrm{mM}$ of mediator (polyoxometalate or HBT) were introduced. The oxidation procedure was carried out using $150-\mathrm{cm}^{3}$-capacity sealed stainless steel dye pots, housed in a dyeing machine (AHIBA Spectradye, from Datacolor) at $50{ }^{\circ} \mathrm{C}$ for $2 \mathrm{~h}$. Color changes of catechol solutions resulting from oxidative reactions were analyzed by UV-Vis spectrophotometry using a diode-array J\&M Tidas spectrophotometer (J\&M Analytische Mess und Regeltechnik GmbH, Germany) before and after treatment.

The reaction pots for fabric incubation were also set up using the same conditions. The bath ratio was consistently set at 1:20 (fabric to liquor). Fabrics color strength was determined using a reflectance-measuring apparatus Spectraflash 600 (Datacolor) equipped with the standard illuminant D65 (LAV/Spec. Excl., d/8, $\mathrm{D}_{65} / 10^{\circ}$ ). The data were expressed as $k / s$ values. Each sample was measured five times, and the data were averaged automatically by the apparatus.

The level of polymer attachment to flax fabrics was further tested in terms of color fastness tests such as washing, rubbing, and light fastness. Washing fastness test was carried out following the EN ISO 105-C06 1999 standard method. A multi-fiber fabric was attached to the treated samples and processed in the same pot to detect color migration. For the rubbing fastness tests, the ASTM D2054-99 2004 standard method was run at dry and wet conditions using a crockmeter equipment. Accelerated Weathering Tester (QUV) Spray LU-0819 from QPANEL, equipped with UVA-340 lamp, was used for light fastness test at $70{ }^{\circ} \mathrm{C}$ and $77 \mathrm{~W} \mathrm{~m}^{-2}$ of irradiation. Exposure of five cycles of $8 \mathrm{~h}$ each was applied on samples until remarkable color degradation was observed. Each flat plaque was holding two samples of standard sizes $(75 \times$ $150 \mathrm{~mm})$. The change of color was presented as color resistance rate.

\section{Size exclusion chromatography}

An amount of $5 \mathrm{mg}$ of each obtained polymer was dissolved in $500 \mu \mathrm{L}$ of $0.1 \mathrm{M} \mathrm{NaNO}_{3}$ aqueous solution at $20{ }^{\circ} \mathrm{C}$ during $60 \mathrm{~min}$ reaching a sample concentration of about $1 \%$. The size exclusion chromatography (SEC) analysis was carried out using two PL aquagel-OH MIXED $8 \mu \mathrm{m} 300 \times 7.5 \mathrm{~mm}$ columns protected by a PL aquagel-OH Guard $8 \mu \mathrm{m}$ pre-column on a PL-GPC 110 system (Polymer Laboratories, UK). The columns, injector system, and the detector (RI) were maintained at $35{ }^{\circ} \mathrm{C}$ during the analysis. The eluent $\left(0.1 \mathrm{M} \mathrm{NaNO}_{3}\right)$ was pumped at a flow

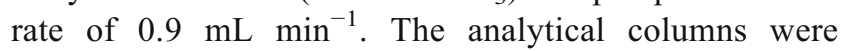
calibrated with pullulans (Polymer Laboratories, UK) in the range 1.7-300.0 $\mathrm{kDa}$. The injected volume was $100 \mu \mathrm{L}$. 
ESI-MS analysis

Electrospray ionization mass spectra (ESI-MS), acquired in a negative mode, were carried out on a Micromass (Manchester, UK) Q-TOF2 hybrid tandem mass spectrometer. Samples were introduced at a flow rate of $10 \mu \mathrm{L} \mathrm{min}{ }^{-1}$ into the ESI source. In the MS experiments, the time-of-flight (TOF) mass resolution was set to approximately 9,000. For ESI analysis, aqueous solutions of polycatechols were diluted in methanol-water $(50: 50, v / v)$ solution. The cone voltage was $35 \mathrm{~V}$, and the capillary voltage was $3 \mathrm{kV}$. The source temperature was $150{ }^{\circ} \mathrm{C}$. The data were processed using MassLynx software (version 4.0). MS/MS spectra were obtained using argon as the collision gas with the collision energy set between 35 and $65 \mathrm{~V}$.

\section{Results}

UV-Vis spectrophotometry of catechol oxidates

The solutions of catechol oxidized either by laccase or LMS with different polyoxometalates (POMs) as mediators were monitored by UV-Vis spectrophotometry (Fig. 1). The changes in the UV-Vis region were recorded using the acetate buffer pH 5 as a reference. The absorption bands from enzyme, catechol, polyoxometalates, and HBT in the buffer solution were also analyzed to verify their particular contribution to the color of solution (Fig. 1). In effect, for the POMs used in this study, $\mathrm{K}_{5}\left[\mathrm{SiW}_{11} \mathrm{~V}^{\mathrm{V}} \mathrm{O}_{40}\right] \cdot 11 \mathrm{H}_{2} \mathrm{O}\left(\mathrm{POM} \mathrm{A}\right.$ ) and $\mathrm{H}_{5}\left[\mathrm{PMo}_{10}\right.$ $\left.\mathrm{V}_{2}{ }^{\mathrm{V}} \mathrm{O}_{40}\right] \cdot 13 \mathrm{H}_{2} \mathrm{O}$ (POM B), possessing yellow and orange color in solution, respectively, no remarkable absorption bands in the visible region have been detected, in agreement with the $3 d^{0}$ electronic configuration of $\mathrm{V}(\mathrm{V})$ in these POMs.

The shapes of the UV-Vis bands in solutions of catechol oxidized by laccase and LMS were very similar though the intensity of absorption varied. The spectra presented, in comparison to the spectrum of catechol, the increase of absorbance at wavelengths higher than $300 \mathrm{~nm}$ that might correspond to a new molecular arrangement and eventual polymer formation. All the solutions incubated with laccase and LMS presented new bands at 315 and $365 \mathrm{~nm}$. The remarkable increase of absorption intensity in the visible region after incubation could be explained by enzymatic polymerization reaction. The small new peak detected at around $650 \mathrm{~nm}$ in the visible region can be explained by the oxidative polymerization of phenol molecules catalyzed by laccase and resulting in generation of chromophore structures (Kim et al. 2007a).

\section{Catechol polymerization assessed by SEC and ESI-MS}

The polymers produced with laccase-POM system were perfectly soluble in aqueous solution (transparent solution). (a)

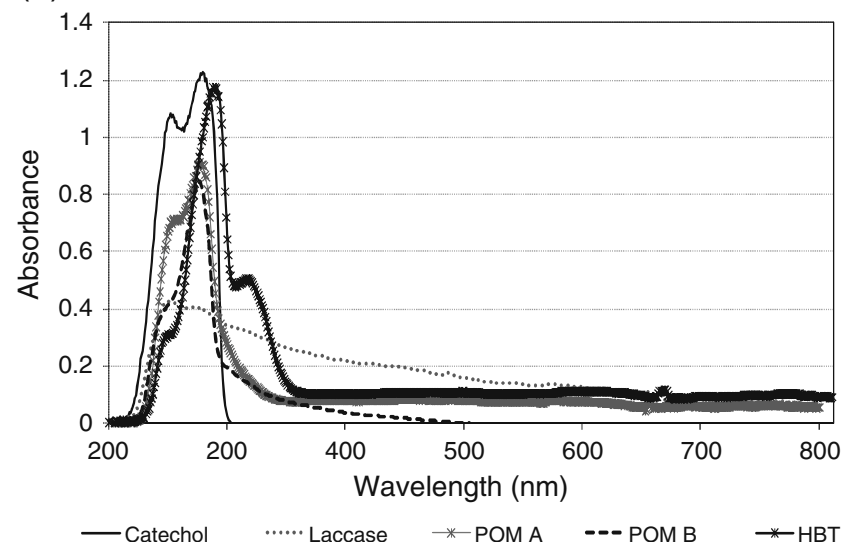

(b)

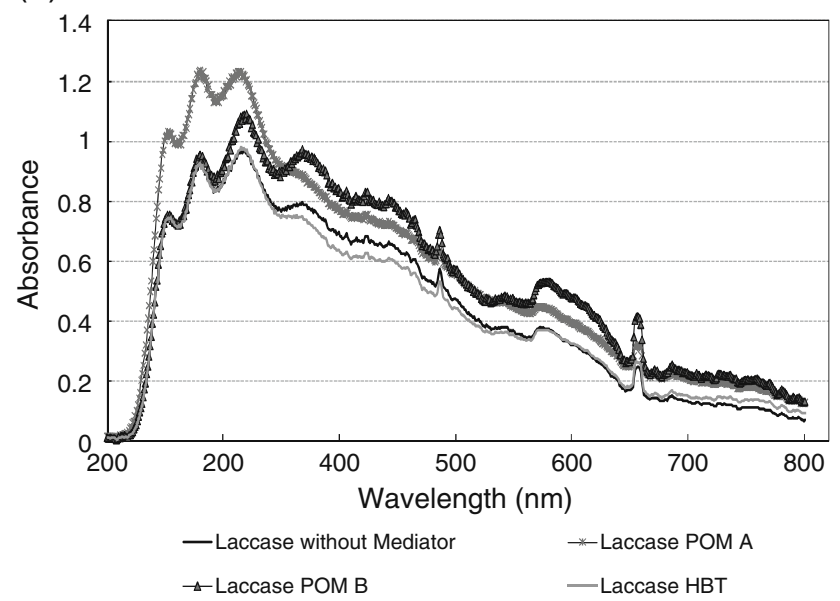

Fig. 1 UV-Vis spectra, measured by UV diode-array spectrophotometry: spectrum of single reaction solutions monitored with acetate buffer (a) and spectrum of the oxidized solutions after incubation at $50{ }^{\circ} \mathrm{C}$ for $2 \mathrm{~h}$ (ten times diluted due to their strong absorption intensity) (b). POM $A, \mathrm{~K}_{5}\left[\mathrm{SiW}_{11} \mathrm{~V}^{\mathrm{V}} \mathrm{O}_{40}\right] \cdot 11 \mathrm{H}_{2} \mathrm{O} ; P O M B$, $\mathrm{H}_{5}\left[\mathrm{PMo}_{10} \mathrm{~V}_{2}{ }^{\mathrm{V}} \mathrm{O}_{40}\right] \cdot 13 \mathrm{H}_{2} \mathrm{O}$

However, the other polycatechols produced by laccaseHBT-mediated polymerization or catalyzed by laccase alone were dissolved at $\mathrm{pH} 10-11$ only (adjusted b0y $\mathrm{NaOH})$. The weight-average molecular weights $\left(M_{\mathrm{w}}\right)$ varied from 3,000 to 4,000 Da, and the number-average molecular weights $\left(M_{\mathrm{n}}\right)$ from 2,700 to 3,600 Da as assessed by SEC. The data on molecular weights are presented in Table 1.

Enzymatic catalysis of catechol polymerization in the presence of POMs showed the formation of higher molecular weight compounds than that with laccase alone with similar polydispersity (Fig. 2, Table 1). This indicates a synergistic catalytic effect emerged by the combination of laccase and POMs. The formation of polymers was additionally confirmed by ESI-MS (data not shown) showing the molecular masses of dissolved polycatechols from several hundreds to more than 1,500 Da. Figure 3 
Table 1 Molecular weight of polymers obtained by polymerization of catechol with laccase in the presence or absence of mediators

\begin{tabular}{llll}
\hline Reaction system $^{\mathrm{a}}$ & $M_{\mathrm{w}}(\mathrm{Da})$ & $M_{\mathrm{n}}(\mathrm{Da})$ & $P$ \\
\hline LAC & 2,990 & 2,660 & 1.12 \\
POM A+LAC & 3,990 & 3,590 & 1.11 \\
POM B+LAC & 3,600 & 3,230 & 1.11 \\
HBT + LAC & 3,280 & 2,940 & 1.11 \\
\hline
\end{tabular}

${ }^{\text {a }}$ Designation for the reaction system: $L A C$, laccase; $P O M A$, $\mathrm{K}_{5}\left[\mathrm{SiW}_{11} \mathrm{~V}^{\mathrm{V}} \mathrm{O}_{40}\right] ;$ POM $B, \mathrm{H}_{5}\left[\mathrm{PMo}_{10} \mathrm{~V}_{2}{ }^{\mathrm{V}} \mathrm{O}_{40}\right]$

shows the schematic representation of catechol polymerization via LMS. The polymer is formed via coupling of phenoxy radical mesomeric structures obtained in oneelectron oxidation with mediator.

Enzymatic catalysis of catechol polymerization in the presence of POMs produced higher molecular weight compounds when compared to the polymerization with HBT as mediator (Fig. 2, Table 1). This can be explained by the eventual higher number of redox cycles occurred with POMs than with HBT due to their better robustness under oxidative catalysis (Castro et al. 2002). Noteworthy the molecular weight of polycatechol obtained in the presence of POM A $\left(\mathrm{K}_{5}\left[\mathrm{SiW}_{11} \mathrm{~V}^{\mathrm{V}} \mathrm{O}_{40}\right]\right)$ was higher than that obtained with POM B $\left(\mathrm{H}_{5}\left[\mathrm{PMo}_{10} \mathrm{~V}_{2}{ }^{\mathrm{V}} \mathrm{O}_{40}\right]\right)$.

$k / s$ estimation of flax fabric coated with polycatechol

In our previous work, the catechol polymerized by laccase was efficiently applied onto the functionalized cotton surface with a high level of adhesion (Kim et al. 2007a,

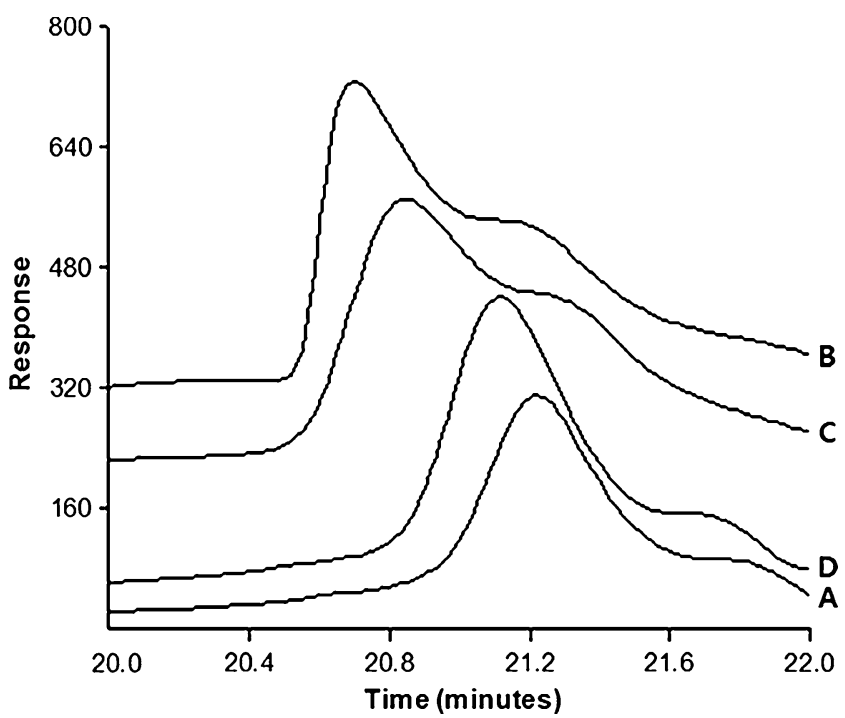

Fig. 2 Molecular weight distribution of polycatechol obtained by laccase catalysis in the presence/absence of mediators as obtained from SEC (laccase alone $(A)$, with POM $\mathrm{A}\left(\mathrm{K}_{5}\left[\mathrm{SiW}_{11} \mathrm{~V}^{\mathrm{V}} \mathrm{O}_{40}\right]\right)(\mathrm{B})$, with POM B $\left(\mathrm{H}_{5}\left[\mathrm{PMo}_{10} \mathrm{~V}_{2}{ }^{\mathrm{V}} \mathrm{O}_{40}\right]\right)(\mathrm{C})$, with HBT (D))

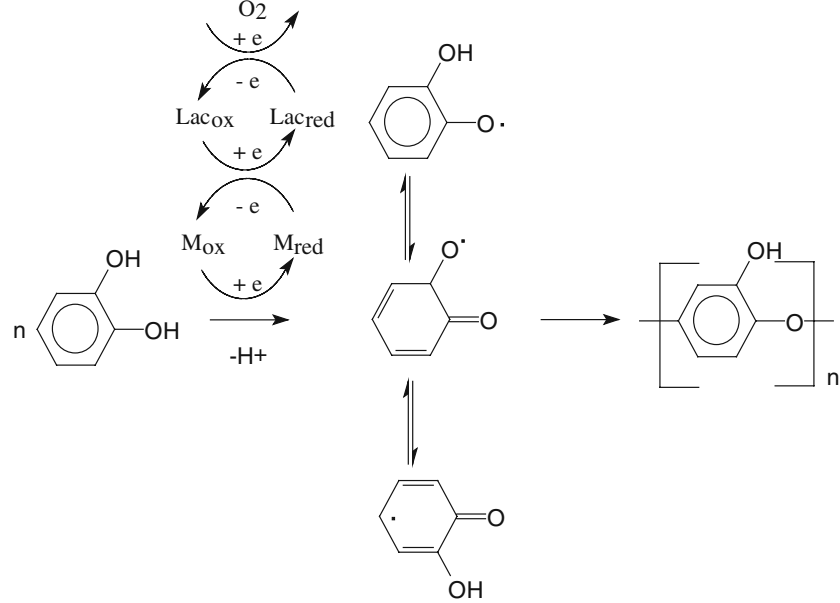

Fig. 3 Schematic representation of catechol polymerization in LMS ( $M$ and $L a c$ refer to mediator and laccase, respectively). Polymer is formed via coupling of phenoxy radical mesomeric structures obtained in one-electron oxidation with mediator

b, 2008). In the present study, the alkaline scoured flax fabrics were used as substrate for the coloration. These fabrics contain phenolic compounds such as lignin and flavonoids that provide natural color to the fabrics (Kim et al. 2007a; Mita et al. 2003). Moreover, this coloration is greater when it is assessed on the solely scoured fabric when compared to scoured bleached fabric. Color generation emerges during the interaction between phenolic compounds in the reaction media and those naturally present at the surface of the fabrics (Kim et al. 2008).

The $k / s$ values (Table 2) were higher when the coloration was carried out with polycatechol formed in the reaction system laccase-POM A when compared to that using the polycatechol formed in the reaction involving solely laccase. POM A played a positive role in LMS, promoting the polymerization of catechol, and presented a synergistic effect on polymer adsorption onto the surface of fabrics. On the other hand, the $\mathrm{k} / \mathrm{s}$ values obtained for the fabric incubated with the solution in which catechol oxidation by laccase was mediated by POM B were lower than those obtained using the solution of polycatechol obtained by oxidation with laccase alone. The different redox properties of POMs could affect the efficiency of the catechol oxidation rate and the polymer structure as discussed above.

The $k / s$ values are presented in terms of color fixation ratio $\left(T_{k / s}\right)$ (Table 2), determined by Eq. (1):

$T_{k / s}=\left((k / s)_{\mathbf{2}} /(k / s)_{1}\right) \times \mathbf{1 0 0} \%$

where $(k / s)_{1}$ and $(k / s)_{2}$ are the color strength values of the colorized samples before and after extraction (washing at boiling temperature, for $10 \mathrm{~min}$ using dyeing apparatus), respectively. This parameter allows the estimation of the real polymer affinity to the surface of fabrics (Matyjas and 
Table 2 Fixation ratio of flax fabric samples colored polycatechol obtained by polymerization with laccase and LMS

\begin{tabular}{llll}
\hline Reaction system $^{\mathrm{a}}$ & $(k / s)_{1}$ & $(k / s)_{2}$ & Fixation ratio (\%) \\
\hline LAC & 6.83 & 4.86 & 71.16 \\
POM A+LAC & 7.29 & 5.96 & 81.76 \\
POM B+LAC & 5.09 & 3.81 & 74.85 \\
HBT+LAC & 7.84 & 5.91 & 75.38
\end{tabular}

All the fabrics samples were analyzed before and after washing process, i.e., at boiling temperature for $10 \mathrm{~min}$ using Ahiba dyeing machine; $(k / s)_{1}$ : before washing process; $(k / s)_{2}$ : after washing process

${ }^{a}$ Designation for the reaction system: $L A C$, laccase; POM A, $\mathrm{K}_{5}\left[\mathrm{SiW}_{11} \mathrm{~V}^{\mathrm{V}} \mathrm{O}_{40}\right] ;$ POM $B, \mathrm{H}_{5}\left[\mathrm{PMo}_{10} \mathrm{~V}_{2}{ }^{\mathrm{V}} \mathrm{O}_{40}\right]$

Rybicki 2003). Interestingly, samples colored with polycatechol formed in the presence of POM A presented higher fixation ratio value $(81.8 \%)$ when compared to those obtained with POM B and with conventional HBT mediator (Table 2).

\section{Coloration durability}

The new polymers obtained were applied onto flax fabrics, and good levels of durability were obtained after rubbing fastness testing (Table 3) as well as after washing fastness tests (4-5) (Table 4). The exposition to light was also experimented, and the results showed some color degradation after colored fabrics exposition (Fig. 4).

\section{Discussion}

Laccases are able to catalyze the oxidation of various aromatic compounds through an oxidative coupling reaction and concomitantly reducing molecular oxygen to water. The oxidation of substrates typically involves the formation of a free cation radical after the transfer of a single electron to laccase. The radical formed by laccase oxidation can further react by a non-enzymatic oxidation (Johannes and Majcherczyk 2000). The oxidation of catechol was catalyzed by laccase resulting in the formation

Table 3 Rubbing fastness results at dry/wet conditions using a crockmeter equipment

\begin{tabular}{lllll}
\hline & LAC & POM A+LAC & POM B +LAC & HBT + LAC \\
\hline Dry & 5 & 5 & 5 & 5 \\
Wet & 3 & 4 & 5 & $3-4$ \\
\hline
\end{tabular}

All the tests were performed against bleached cotton as a reference (evaluation: 5 , excellent; 1 , very poor)

$L A C$, laccase; POM A, $\mathrm{K}_{5}\left[\mathrm{SiW}_{11} \mathrm{~V}^{\mathrm{V}} \mathrm{O}_{40}\right]$; POM B, $\mathrm{H}_{5}\left[\mathrm{PMo}_{10} \mathrm{~V}_{2}{ }^{\mathrm{V}} \mathrm{O}_{40}\right]$
Table 4 Washing fastness results

\begin{tabular}{lllll}
\hline & LAC & POM A+LAC & POM B+LAC & HBT+LAC \\
\hline Wool & $4-5$ & $4-5$ & $4-5$ & $4-5$ \\
Polyacrylic & $4-5$ & $4-5$ & $4-5$ & $4-5$ \\
Polyester & 5 & $4-5$ & $4-5$ & $4-5$ \\
Polyamide & 5 & $4-5$ & 5 & 5 \\
Cotton & 4 & 4 & 4 & $4-5$ \\
Acetate & 4 & 4 & $4-5$ & 4 \\
\hline
\end{tabular}

The color migration was measured on the multi-fibers as references using spectrometry measurements; evaluation: 5 , excellent; 1 , very poor

$L A C$, laccase; POM A, $\mathrm{K}_{5}\left[\mathrm{SiW}_{11} \mathrm{~V}^{\mathrm{V}} \mathrm{O}_{40}\right] ; P O M B, \mathrm{H}_{5}\left[\mathrm{PMo}_{10} \mathrm{~V}_{2}{ }^{\mathrm{V}} \mathrm{O}_{40}\right]$

of dark-colored compounds due to the arrangement of conjugated structures along the main chain (polyphenols) (Pilz et al. 2003; Johannes and Majcherczyk 2000).

The results attained show that the molecular weight of polycatechol obtained in the presence of POM A $\left(\mathrm{K}_{5}\left[\mathrm{SiW}_{11} \mathrm{~V}^{\mathrm{V}} \mathrm{O}_{40}\right]\right)$ was higher than the one obtained with POM B $\left(\mathrm{H}_{5}\left[\mathrm{PMo}_{10} \mathrm{~V}_{2}{ }^{\mathrm{V}} \mathrm{O}_{40}\right]\right)$ (Fig. 2, Table 1). Considering the easier re-oxidation of POM $\mathrm{B}$ in catalytic system laccase/POM than that of POM A, those molecular weight features cannot be explained by the number of redox cycles only. It seems that both POMs revealed slightly different polymerization mechanisms. Thus, POM A is a known oneelectron oxidant providing an outer-sphere oxidation reaction of substituted phenols similarly to metalloenzymes (Galli et al. 2007). In contrast, POM B can provide not only one-electron oxidation of phenolic substrate but also two sequential one-electron oxidations with further formation of hexadienyl cations, i.e., promoting not only radical but also ionic polymerization pathways with formation of $\mathrm{C}-\mathrm{C}$ linkages (poly(phenylenes)) (Galli et al. 2007). The hydroxylation of aromatic nuclei is a competitive reaction that may be also responsible for the termination of polymerization, thus decreasing the molecular weight of polycatechol.

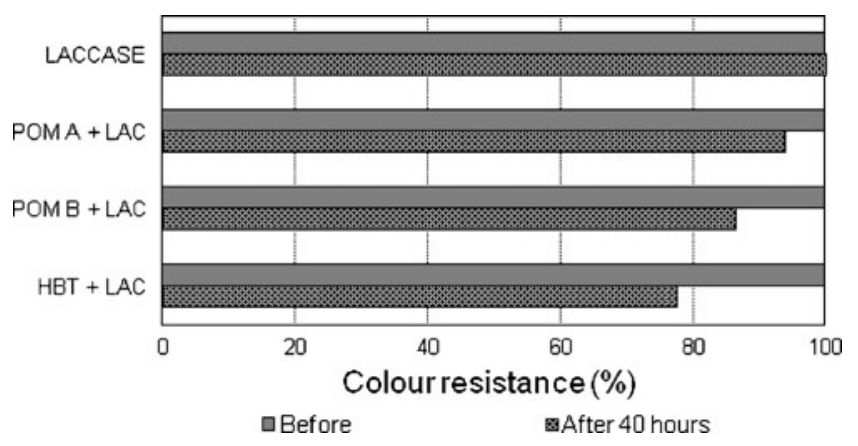

Fig. 4 Weathering fastness results (samples were tested using Accelerated Weathering Tester (QUV) Spray LU-0819 (five cycles of $8 \mathrm{~h}$ each, total $40 \mathrm{~h}$ at $\left.70{ }^{\circ} \mathrm{C}\right)$. POM A, $\mathrm{K}_{5}\left[\mathrm{SiW}_{11} \mathrm{~V}^{\mathrm{V}} \mathrm{O}_{40}\right]$; POM B, $\mathrm{H}_{5}\left[\mathrm{PMo}_{10} \mathrm{~V}_{2}{ }^{\mathrm{V}} \mathrm{O}_{40}\right]$ 
The efforts on structural elucidation of polycatechols by tandem ESI-MS (ESI-MS/MS) were not very successful. Despite of expected well-defined series of signals in negative mode ESI-MS spectra, according to commonly accepted semi-regular structure of polycatechols obtained via coupling of phenoxy radical resonance structures in the presence of laccase (Fig. 3), the formers were not clearly detected. This indicates that the polymerization of catechol occurred via different reactive sites and led to rather heterogeneous polymer with a large variety of structures. This point, however, needs further studies.

Recently, the enzymatic coloration of wool, cotton, and human hair via polymerization of various reaction substrates by laccase was widely investigated (Kim et al. 2007a, b, 2008; Shin et al. 2001). The biomimetic process using oxidative enzymes is being exploited for the in situ production of biopolymers and further application onto fabrics, thus replacing chemical treatments within an environmentally friendly concept. Following the same strategy, the solutions of polycatechol obtained by oxidative polymerization with laccase alone, and with POM, were applied on the coloration of flax fabrics which should be of polyphenolic origin. Generally, the polyphenols obtained by enzymatic oxidation possess structures which are composed of a mixture of phenylene and oxyphenylene units. They are formed from the $\mathrm{C}-\mathrm{C}$ and $\mathrm{C}-\mathrm{O}$ coupling of phenols, respectively, resulting in high molecular weight compounds (Shin et al. 2001; Madzak et al. 2006; Gianfreda et al. 2003).

Hence, an enhancement of coloration and colorant fixation may be considered a result of in situ grafting between biopolymers formed in solution and those presenting in fabric.

The polymers adsorbed onto the flax fabrics were tested in terms of color resistance on rubbing stress. After rubbing tests following the ASTM D2054-99 standard method, the white cotton fabric references were measured by spectrophotometry. The results obtained as grades from 5 (excellent) to 1 (very poor) are presented in Table 3. All the fabrics colored by polycatechols obtained with laccase and with LMS showed excellent color resistance against the rubbing stress under dry conditions. However, when no POMs were applied as mediators i.e., in the case of laccase alone or with HBT, a color staining was detected on reference cottons.

The washing fastness, the most required property for textiles color fixation, was carried out following EN ISO 105-C06 standard method. The multi-fibers (possessing six different fibers: wool, polyacrylic, polyester, polyamide, cotton, and acetate) were set as reference fabric to estimate the migration of color from the colored flax samples. Most of the fabrics presented good color resistance grade $(4,4-5)$ (Table 4). Polymers produced by laccase and LMS have strong affinity while attached to the fabric due to their new properties obtained after oxidation such as insolubility in water and high molecular weight (Gianfreda et al. 2003; Mita et al. 2003).

In our previous work, the cotton fabric colored with enzymatically produced polymers showed quite poor resistance on the light test (Kim et al. 2008). In this work, the color degradation degree was estimated for $40 \mathrm{~h}$ (five cycles of $8 \mathrm{~h}$ each), since most of the color vanishings occur during the first cycles. After $40 \mathrm{~h}$, the color degradation rate was obtained by measuring the color intensity (Fig. 4). When submitted to light conditions, the flax fabrics colored by polycatechols obtained with laccase only, showed higher resistance to color degradation when compared with the other fabrics colored by polycatechols from LMS. This is due to the fact that the samples obtained with laccase alone presented much lower color intensity before testing, decreasing therefore the probability to lose color, when compared with the highly colored samples obtained with LMS..

The values obtained for the fabric samples incubated with the solutions from the catechol oxidation by LMS (POM A) followed the same tendency as in previous trials. In relation to other reaction systems, POM A/ laccase system seems to promote the highest colorant fixation level since the samples loose only $10 \%$ of their color after $40 \mathrm{~h}$ of exposure. At the same time, the fabrics treated with other LMS revealed a color decrease in the range of $\approx 20 \%$.

In summary, polyoxometalates (POMs) were suggested to be the appropriate mediators in laccase-mediator system (LMS) for the oxidative polymerization purposes showing synergistic behavior when applied in the presence of laccase. POMs showed better oxidative catalytic ability in LMS for the catechol oxidative polymerization, when compared to the conventional organic mediator HBT, thus providing polymers with higher molecular weight. The analysis of polycatechols by ESI-MS evidenced their significant structural heterogeneity.

The polycatechols were applied as dyes in textile coloration. A high flax fabric coverage degree was achieved with acceptable values of washing resistance while applying the polycatechols synthesized with LMS. Again, better coloration performance was observed for polycatechols obtained with POMs as redox mediators when compared to those with organic mediator (HBT). It may be proposed that novel phenolic polymers can provide to textile fabrics some particular functional properties such as improved hydrophobicity, specific color improving, coloration, and antimicrobial/ antioxidant properties.

Acknowledgments The authors would like to acknowledge the BIORENEW European Project-Sixth Framework European Program. 


\section{References}

Aktas N, Tanyolac A (2003) Kinetics of laccase-catalyzed oxidative polymerization of catechol. J Mol Catal B Enzym 22:61-69

Balakshin M, Evtuguin DV, Neto C, Cavaco-Paulo A (2001) Polyoxometalates as mediators in the laccase catalysed deligninfication. J Mol Catal B Enzym 16:131-140

Castro A, Evtuguin DV, Xavier A (2002) Degradation of biphenyl lignin model compounds by laccase of Trametes versicolor in the presence of 1-hydroxybenzotriazole and heteropolyanion $\left[\mathrm{SiW}_{11} \mathrm{VO}_{40}\right]^{5-}$. J Mol Catal B Enzym 22:13-20

DDe-L L, Burkholder E, Cronin L (2007) Polyoxometalate clusters, nanostructures and materials: from self assembly to design materials and devices. Chem Soc Rev 36:105-121

Domaille PJ (1984) 1- and 2-dimensional tungsten-183 and vanadium51 NMR characterization of isopolymetalates and heteropolymetalates. J Am Chem Soc 106:7677-7687

Galli C, Gentili P, Pontes AS, Gamelas JAF, Evtuguin D (2007) Oxidation of phenols employing polyoxometalates as biomimetic models of the activity of phenoloxidase enzymes. New J Chem 31:1461-1467

Gamelas JAF, Tavares A, Evtuguin DV, Xavier A (2005) Oxygen bleaching of kraft pulp with polyoxometalates and laccase applying novel multi-stage process. J Mol Catal B Enzym 33:57-64

Gamelas JAF, Pontes AS, Evtuguin DV, Xavier AMB (2007) New polyoxometalate-laccase integrated system for kraft pulp delignification. Biochem Eng J 33:141-147

Gaspar A, Evtuguin DV, Neto CP (2004) Polyoxometalate catalyzed oxygen delignification of kraft pulp - a pilot plant experience. J Ind Eng Chem 43:7754-7761

Gaspar A, Gamelas JAF, Evtuguin DV, Neto CP (2007) Alternatives for lignocellulosic pulp delignification using polyoxometalates and oxygen: a review. Green Chem 9:717-730

Gianfreda L, Sannino F, Rao MA, Bollag J (2003) Oxidative transformation of phenols in aqueous mixtures. Water Res 37:3205-3215

Gronqvist S, Suurnakki A, Niku-Paavola ML, Kruus K, Buchert J, Viikari L (2003). In: Mansfield SD, Saddler JN (eds) Applications of enzymes to lignocellulosics, ACS symposium series. $855: 46-65$

Johannes C, Majcherczyk A (2000) Natural mediators in the oxidation of polycyclic aromatic hydrocarbons by laccase mediator systems. Appl Environ Microbiol 66:524-528
Kim SY, Moldes D, Cavaco-Paulo A (2007a) Laccase for enzymatic coloration of unbleached cotton. Enzyme Microb Technol 40:1788-1793

Kim SY, Zille A, Murkovic M, Guebitz GM, Cavaco-Paulo A (2007b) Enzymatic polymerization on the surface of functionalized cellulose fibers. Enzyme Microb Technol 40:1782-1787

Kim SY, Lopez C, Guebitz GM, Cavaco-Paulo A (2008) Biological coloration of flax fabrics with flavonoids using laccase from Trametes hirsuta. Eng Life Sci 8:324-330

Kozhevnikov IV (1998) Catalysis by heteropoly acids and multicomponent polyoxometalates in liquid-phase reactions. Chem Rev 98:171-198

Madzak C, Mimmi MC, Caminade E, Brault A, Baumberger S, Briozzo P, Mougin C, Jolivalt C (2006) Shifting the optimal $\mathrm{pH}$ of activity for a laccase from the fungus Trametes versicolor by structure-based mutagenesis. Prot Eng Des Sel 19:77-84

Mattinen ML, Suorti T, Gosselink R, Argyropoulos DS, Evtuguin D, Suurnäkki A, de Jong E, Tamminen T (2008) Polymerization of different lignins by laccase. Bioresources 3:549-565

Matyjas E, Rybicki E (2003) Novel reactive red dyes. AUTEX Res J 3:90-95

Mita N, Tawaki S, Uyama H, Kobayashi S (2003) Laccase-catalyzed oxidative polymerization of phenols. Macromol Biosci 3:253-257

Morozova OV, Shumakovich GP, Shleev SV, Yaroplov YI (2007) Laccase-mediator systems and their applications: a review. Appl Biochem Microbiol 43:523-535

Neumann R (1998) Polyoxometalate complexes in organic oxidation chemistry. Prog Inorg Chem 47:317-370

Pilz R, Hammer E, Schauer F, Kragl U (2003) Laccase-catalysed synthesis of coupling products of phenolic substrates in different reactors. Appl Microbiol Biotechnol 60:708

Riva S (2006) Laccases: blue enzymes for green chemistry. Trends Biotechnol 24:219-226

Shin H, Guebitz GM, Cavaco-Paulo A (2001) "In Situ” enzymatically prepared polymers for wool coloration. Macromol Mater Eng 286:691-694

Tavares A, Gamelas JAF, Gaspar A, Evtuguin DV, Xavier A (2004) A novel approach for the oxidative catalysis employing polyoxometalate-laccase system: application to the oxygen bleaching of kraft pulp. Catal Commun 5:485-489

Tsigdinos GA, Hallada CJ (1968) Molybdovanadophosphoric acids and their salts. I. Investigation of methods of preparation and characterization. Inorg Chem 7:437-441 